\title{
Increased Abundance of the Receptor-type Protein-Tyrosine Phosphatase LAR Accounts for the Elevated Insulin Receptor Dephosphorylating Activity in Adipose Tissue of Obese Human Subjects
}

Faiyaz Ahmad, Robert V. Considine, and Barry J. Goldstein

From the Dorrance H. Hamilton Research Laboratories, Division of Endocrinology and Metabolic Diseases, Department of Medicine, Jefferson Medical College, Thomas Jefferson University, Philadelphia, Pennsylvania 19107

\begin{abstract}
Protein-tyrosine phosphatases (PTPases) have an essential role in the regulation of the steady-state phosphorylation of the insulin receptor and other proteins in the insulin signalling pathway. To examine whether increased PTPase activity is associated with adipose tissue insulin resistance in human obesity we measured PTPase enzyme activity towards the insulin receptor in homogenates of subcutaneous adipose tissue from a series of six lean and six nondiabetic, obese (body mass index $>30$ ) subjects. The obese subjects had a mean 1.74-fold increase in PTPase activity ( $P$ $<0.0001$ ) with a striking positive correlation by linear regression analysis between PTPase activity and body mass index among all of the samples $(R=0.918 ; P<0.0001)$. The abundance of three candidate insulin receptor PTPases in adipose tissue was also estimated by immunoblot analysis. The most prominent increase was a $\mathbf{2 . 0 3}$-fold rise in the transmembrane PTPase LAR $(P<0.001)$. Of the three PTPases examined, only immunodepletion of LAR protein from the homogenates with neutralizing antibodies resulted in normalization of the PTPase activity towards the insulin receptor, demonstrating that the increase in LAR was responsible for the enhanced PTPase activity in the adipose tissue from obese subjects. These studies suggest that increased PTPase activity towards the insulin receptor is a pathogenetic factor in the insulin resistance of adipose tissue in human obesity and provide evidence for a potential role of the LAR PTPase in the regulation of insulin signalling in disease states. (J. Clin. Invest. 1995. 95:2806-2812.) Key words: insulin resistance - tyrosine phosphorylation - tyrosine kinase $\cdot$ hormone signalling
\end{abstract}

\section{Introduction}

Defective insulin signalling in its target tissues is a major feature of the pathophysiology of human obesity and non-insulin-dependent diabetes mellitus $(1-3)$. While major advances have

Address correspondence to Barry J. Goldstein, M.D., Ph.D., Director, Division of Endocrinology and Metabolic Diseases, Jefferson Medical College, Room 349 Jefferson Alumni Hall, 1020 Locust Street, Philadelphia, Pennsylvania 19107. Phone: 215-955-1272; FAX: 215-923-7932. E-mail: b_goldstein@lac.jci.tju.edu

Received for publication 21 November 1994 and in revised form 22 February 1995.

J. Clin. Invest.

(c) The American Society for Clinical Investigation, Inc.

0021-9738/95/06/2806/07 \$2.00

Volume 95, June 1995, 2806-2812 recently been made in our understanding of the central role for reversible tyrosine phosphorylation of the insulin receptor and its cellular substrate proteins in the mechanism of insulin action (4), we still do not have a clear picture of how these events are regulated, or of molecular defects that may lead to the insulin resistance observed in disease states.

Several recent studies have provided evidence that proteintyrosine phosphatases (PTPases) ${ }^{1}$ have an integral role in the regulation of insulin signal transduction (5). PTPases can dephosphorylate and attenuate the active (autophosphorylated) form of the insulin receptor tyrosine kinase. In addition, PTPases may modulate post-receptor signalling by dephosphorylating the phosphotyrosyl form of cellular substrate proteins for the insulin receptor such as IRS-1 and Shc, which signal to downstream enzymes as "docking" proteins that bind and activate a number of $s r c$-homology 2 ( $\mathrm{SH} 2$ ) domain-containing signalling proteins (4). Thus, the opposing effects of phosphorylation by the insulin receptor kinase and dephosphorylation by cellular PTPases will regulate the state of tyrosine phosphorylation of signalling proteins in the insulin action pathway.

From the expanding superfamily of protein-tyrosine phosphatases (6), work in our laboratory and others has implicated the tandem-domain transmembrane enzyme LAR (7) and the intracellular, single domain PTPases 1B $(8,9)$ and SH-PTP2/ syp (also termed PTP1D or PTP2C) $(10,11)$, as candidate PTPases for the regulation of the insulin action pathway. In addition to being relatively prominent PTPases in adipose tissue and other insulin-sensitive tissues, these enzymes have catalytic activity towards the insulin receptor or its substrate proteins in studies done both in vitro and in vivo $(5,12)$. Of these PTPases, we have been particularly interested in the transmembrane PTPase LAR (7) since it is expressed in insulin-sensitive liver, muscle, and adipose tissue (5), it is localized to the membrane fraction of the cell where the insulin receptor is rapidly dephosphorylated $(13,14)$, and it has a catalytic preference for the regulatory phosphotyrosines in the insulin receptor kinase domain (15). Furthermore, reduction of LAR enzyme mass by expression of antisense mRNA in hepatoma cells markedly enhances insulin receptor autophosphorylation and insulin-stimulated phosphatidylinositol 3 '-kinase activity (44). These studies have provided compelling evidence that LAR may be a physiological modulator of insulin signalling.

The present work was undertaken to test the hypothesis that increased PTPase enzyme activity is associated with the insulin resistance of human obesity and whether the abundance of specific PTPase homologs might be associated with the increased

1. Abbreviations used in this paper: BMI, body mass index; LAR, Leukocyte Common Antigen-Related PTPase; PTPase, Protein-tyrosine phosphatase. 
PTPase activity in adipose tissue. We found a strong correlation between body mass index and the PTPase activity towards the insulin receptor in adipose tissue from normal weight and obese subjects. Immunoblot analysis showed that the mass of LAR enzyme protein was markedly increased in the tissue homogenates. Finally, immunodepletion studies demonstrated that the augmented tissue PTPase activity in the obese individuals was largely due to the increased LAR protein. These studies provide further evidence that PTPases, and LAR in particular, play an essential role in the pathogenesis of insulin resistance in adipose tissue in human obesity.

\section{Methods}

Human subjects. Subcutaneous adipose tissue was obtained surgically from human subjects during elective operations. Informed consent was obtained prior to surgery by procedures approved by the Thomas Jefferson University Institutional Review Board.

Preparation of adipose tissue homogenates. Adipose tissue samples were rapidly frozen in liquid nitrogen and stored at $-85^{\circ} \mathrm{C}$ before use. Approximately 10-12 grams of adipose tissue from each patient was homogenized in $50 \mathrm{ml}$ of ice-cold $10 \mathrm{mM}$ Tris- $\mathrm{HCl}$ buffer ( $\mathrm{pH} \mathrm{7.0)}$ containing $0.25 \mathrm{M}$ sucrose, $2 \mathrm{mM}$ EDTA, $1 \mathrm{mM}$ PMSF, $25 \mathrm{mM}$ benzamidine, $10 \mu \mathrm{M}$ leupeptin, and $50 \mathrm{U} / \mathrm{ml}$ aprotinin., with a $4 \mathrm{up} /$ down strokes at setting No. 3 of a Polytron (Brinkmann Instrument, Westbury, NY). The crude homogenate was centrifuged at $3,000 \mathrm{~g}$, and the infranate below the fat cake was removed. To solubilize PTPase enzymes from the particulate compartment into the tissue homogenate, the infranate was made up to $1 \%$ (vol/vol) Triton X-100 and $0.6 \mathrm{M} \mathrm{KCl}$, stirred for $45 \mathrm{~min}$ at $4^{\circ} \mathrm{C}$, and centrifuged at $15,000 \mathrm{~g}$ for 20 min. The resulting supernatant was dialyzed overnight at $4^{\circ} \mathrm{C}$ against the homogenization buffer. Protein was assayed by the method of Bradford (16).

Insulin receptor dephosphorylation. Partially purified insulin holoreceptors were obtained by wheat germ agglutinin-agarose chromatography (17) of solubilized plasma membranes from transfected Chinese hamster ovary cells overexpressing the recombinant human insulin receptor (15). Aliquots of $4 \mathrm{mg}$ protein were autophosphorylated in a $0.45 \mathrm{ml}$ reaction containing $1 \mathrm{mM}$ insulin, $5 \mathrm{mM} \mathrm{MnCl}, 0.1 \mathrm{mM}$ ATP, $180 \mu \mathrm{Ci}$ of $\gamma-\left[{ }^{32} \mathrm{P}\right] \mathrm{ATP}(3,000 \mathrm{Ci} / \mathrm{mmol})$, and $0.1 \%$ (vol/vol) Triton $\mathrm{X}-100$ in $50 \mathrm{mM}$ Hepes buffer at $\mathrm{pH} 7.6$, at $4^{\circ} \mathrm{C}$ for $120 \mathrm{~min}$. Unincorporated $\left[{ }^{32} \mathrm{P}\right]$-ATP was removed by a Bio-Gel P6 spin column, and $25 \mu \mathrm{l}$ aliquots of the labeled receptors were incubated with $40 \mu \mathrm{l}$ of the solubilized adipose tissue homogenate in a $125 \mu$ reaction containing $1 \mathrm{mM}$ DTT and $2 \mathrm{mM}$ EDTA in $50 \mathrm{mM}$ Hepes, $\mathrm{pH} 7.6$, at $30^{\circ} \mathrm{C}$. The reactions were terminated by the addition of $0.5 \mathrm{ml}$ of a chilled stop solution containing $10 \mathrm{mM}$ ATP, $10 \mathrm{mM}$ sodium pyrophosphate, $4 \mathrm{mM}$ EDTA, $100 \mathrm{mM} \mathrm{NaF}, 2 \mathrm{mM}$ sodium vanadate, $0.1 \mathrm{mg} / \mathrm{ml}$ aprotinin, and $2 \mathrm{mM}$ PMSF in $50 \mathrm{mM}$ Hepes buffer, $\mathrm{pH}$ 7.6. After boiling in gel sample buffer containing $100 \mathrm{mM}$ DTT, samples were subjected to electrophoresis in gels containing sodium dodecyl sulfate and $7.5 \%$ polyacrylamide (18). Dephosphorylation of the $95-\mathrm{kD} \beta$-subunit of the insulin receptor was analyzed by direct phosphorimager analysis of the dried gel (Molecular Dynamics, Sunnyvale, CA).

Immunoblot analysis of PTPase abundance. The adipose tissue homogenates ( $40 \mu \mathrm{g}$ protein) were fractionated on gels containing sodium dodecyl sulfate and 7.5\% (for LAR and SH-PTP2) or 10\% (for PTPase $1 B$ ) polyacrylamide in a minigel apparatus (18). Proteins were transferred to nitrocellulose filters $(0.45 \mathrm{~m}$ pore size $)$ at $100 \mathrm{~V}$ for $3 \mathrm{~h}$ in buffer containing 20\% (vol/vol) methanol, $25 \mathrm{mM}$ Tris base and 192 $\mathrm{mM}$ glycine at $\mathrm{pH} 8.3$ (19). Nitrocellulose membranes were then incubated in blocking buffer containing $150 \mathrm{mM} \mathrm{NaCl}, 0.05 \%$ (vol/vol) $\mathrm{NP}-40,5 \%$ (vol/vol) bovine serum albumin, $1 \%$ (wt/vol) ovalbumin,

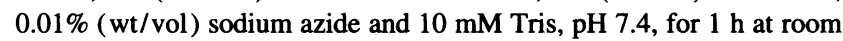
temperature with rocking. The blocking solution was replaced with 150 $\mathrm{mM} \mathrm{NaCl}, 0.05 \%$ ( $\mathrm{vol} / \mathrm{vol}$ ) Tween $20,5 \%$ (wt/vol) bovine serum albumin, $1 \%(\mathrm{wt} / \mathrm{vol})$ ovalbumin, $0.01 \%(\mathrm{wt} / \mathrm{vol})$ sodium azide, and $10 \mathrm{mM}$ Tris, $\mathrm{pH} 7.4$, containing individual PTPase antibodies $(1.0 \mu \mathrm{g} /$ $\mathrm{ml}$ for PTPase1B, $0.5 \mu \mathrm{g} / \mathrm{ml}$ for LAR, or $1.25 \mu \mathrm{g} / \mathrm{ml} \mathrm{SH-PTP2),} \mathrm{and}$ rocking was continued for $2 \mathrm{~h}$. Membranes were washed three times for $10 \mathrm{~min}$ with blotting buffer alone followed by incubation with 2 $\mu \mathrm{Ci}$ of ${ }^{125} \mathrm{I}$-protein $\mathrm{A}$ ( $30 \mathrm{mCi} / \mathrm{mg}$ ) (ICN Biomedicals Inc., Irvine, CA) for $1 \mathrm{~h}$ at room temperature followed by three additional 10-min washes with TBST. Immunoreactive proteins were visualized by direct phosphorimager analysis of the immunoblot (Molecular Dynamics). Protein migration was calibrated with prestained molecular size standards from Bio Rad (Melville, NY).

Polyclonal antiserum to the cytoplasmic domain of recombinant rat LAR was obtained by immunization of rabbits with LAR protein purified from a bacterial expression system (20). In both cases, the antibodies were affinity-purified using Affi-Gel (Bio-Rad) columns containing immobilized purified LAR cytoplasmic domain (21). Polyclonal antiserum to PTPase1B and a monoclonal antibody to SH-PTP2 were obtained from Transduction Laboratories (Lexington, KY). After blotting with the monoclonal antibody, blots were incubated with $150 \mu \mathrm{l}$ rabbit antimouse IgG (Sigma Chemical Co., St. Louis, MO) in $10 \mathrm{ml}$ of blotting buffer, and then washed again before reaction of the immunoblot with labeled protein A.

Immunodepletion studies with PTPase antibodies. In some experiments, homogenates from the obese and control subjects were incubated with excess antibody to each of the three PTPases tested and immunocomplexes were precipitated with trisacryl-protein A beads to deplete the supernatant of individual PTPase enzymes. Normal rabbit IgG was used in place of PTPase antibody in control studies. Four separate experiments were performed for each antibody depletion using the samples from the control and obese subjects. Preliminary experiments with recombinant LAR protein determined that $3 \mu \mathrm{g}$ of affinity-purified LAR antibody would provide approximately a 30 -fold excess of antibody for the depletion of LAR from $40 \mu \mathrm{g}$ of homogenate protein from the obese subjects. Immunoblot analysis of the cleared supernatant demonstrated that this treatment was effective in removing $90-95 \%$ of the LAR enzyme protein from the tissue homogenate samples. Similarly, 80$90 \%$ of the SH-PTP2 protein was immunoprecipitated from human adipose tissue homogenates by $5 \mu \mathrm{g}$ of monoclonal antibody, and 75$80 \%$ of the PTPase1B protein was immunoprecipitated by $7 \mu \mathrm{g}$ of polyclonal antibody (data not shown).

Statistical methods. Data is presented as mean \pm SEM with the indicated number of samples in each group. Correlations were analyzed by simple linear regression analysis, and where applicable, two groups were compared by Student's $t$ test. The immunodepletion study was analyzed by one-way ANOVA with Bonferroni's correction to evaluate the significance of changes among the four groups. Calculations were performed with the SigmaStat PC computing software (Jandel Scientific, San Rafael, CA).

\section{Results}

Subcutaneous adipose tissue samples were obtained during elective surgery from 6 normal weight and 6 obese (BMI $>30$ ) individuals. None of the subjects had overt diabetes mellitus as manifested by hyperglycemia during pre- or post-operative testing, and none were taking oral hypoglycemic medications or insulin. The two groups were not significantly different in age or in their composition by gender or race (Table I).

Homogenates were prepared from the adipose tissue specimens and samples were tested for PTPase activity towards the insulin receptor. Since the PTPase assay was performed with matching amounts of protein from each homogenate sample, the results reflect the specific activity of the PTPase towards the autophosphorylated insulin receptor as substrate. A representative experiment shows that receptor dephosphorylation was markedly increased when incubated with adipose tissue 


\begin{tabular}{|c|c|c|c|c|c|c|c|c|}
\hline & \multicolumn{4}{|c|}{ Lean } & \multicolumn{4}{|c|}{ Obese } \\
\hline & Age & BMI & Sex & Race & Age & BMI & Sex & Race \\
\hline & & $\mathrm{kg} / \mathrm{m}^{2}$ & & & & $\mathrm{~kg} / \mathrm{m}^{2}$ & & \\
\hline & 26 & 23.1 & F & A & 27 & 35.8 & $\mathrm{~F}$ & $\mathbf{H}$ \\
\hline & 30 & 24.5 & F & A & 32 & 38.4 & F & A \\
\hline & 44 & 26.2 & $\mathbf{F}$ & $\mathrm{C}$ & 37 & 40.0 & $\mathbf{M}$ & $\mathrm{C}$ \\
\hline & 47 & 23.7 & $\mathbf{F}$ & $\mathbf{H}$ & 41 & 41.5 & $\mathrm{~F}$ & C \\
\hline & 52 & 25.7 & $\mathbf{M}$ & $\mathrm{C}$ & 45 & 31.1 & $\mathbf{M}$ & A \\
\hline & 73 & 27.4 & $\mathbf{M}$ & $\mathrm{C}$ & 46 & 47.6 & $\mathrm{~F}$ & $\mathrm{C}$ \\
\hline Mean & $45.3 \pm 6.9$ & $25.1 \pm 0.7$ & & & $38 \pm 3.1$ & $39.1 \pm 2.3 *$ & & \\
\hline
\end{tabular}

The age difference is not statistically significant between the lean and obese groups. The abbreviations for race designation is as follows: $A$, AfricanAmerican; $C$, Caucasian; $H$, Hispanic. ${ }^{*} P=0.0001$ vs. lean.

homogenates from the obese individuals (Fig. 1). As a group, the obese individuals had a 1.74-fold increase in the insulin receptor PTPase activity compared to the normal weight subjects $(7975 \pm 351[n=6]$ vs. $13907 \pm 760[n=6]$, respectively $[p=0.00003])$. Furthermore, when tested by linear regression analysis, there was a striking correlation between BMI and the insulin receptor dephosphorylating activity among the adipose tissue homogenates of all of the individuals studied that was highly statistically significant (Fig. 2). These results demonstrated that the extent of obesity is linearly related to the increased insulin receptor dephosphorylating activity in adipose tissue, and may be an important factor in the tissue resistance to insulin action that has been well-characterized in this tissue.

These findings were further extended to determine which of several major candidate PTPases expressed in adipose tissue might account for the increased PTPase activity in the obese subjects. Samples of the adipose tissue homogenates were electrophoresed on polyacrylamide gels and transferred to nitrocellulose filters for immunoblotting. Separate blots using antibodies to PTPase1B, SH-PTP2, and LAR were performed in order to quantitate the abundance of the individual PTPases (Table II). PTPase1B protein levels were only slightly increased on average by 1.22 -fold, albeit with statistical significance. SHPTP2, which has in recent studies been shown to be a positive mediator of insulin signalling and might have been postulated

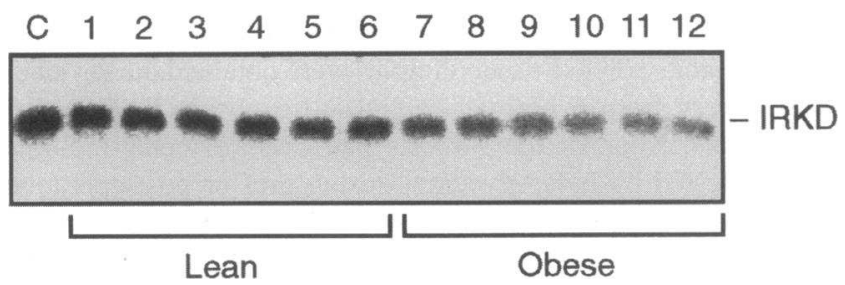

Figure 1. Insulin receptor dephosphorylation by adipose tissue homogenates from normal weight and obese individuals. Homogenates were prepared from intraoperative specimens of subcutaneous adipose tissue from each subject and PTPase activity was assayed by incubation with autophosphorylated, recombinant human insulin receptors as described in Methods. A representative phosphorimage of the dephosphorylated insulin receptors is shown. Lane $C$, control incubation with no homogenate added; lanes $1-6$, lean individuals; lanes $7-12$, obese individuals; IRKD, insulin receptor kinase domain ( $95 \mathrm{kD} \beta$ subunit). to be reduced in insulin-resistant states $(22,23)$, was actually moderately increased by 1.45 -fold in the adipose tissue homogenates from the obese individuals.

Analysis of LAR protein mass by immunoblotting showed a dramatic increase in the obese subjects compared to the normal weight individuals (Fig. 3). Quantitation of the phosphorimage density from all of the patients in the two groups revealed a highly significant mean increase of 2.03 -fold in the adipose tissue of the obese subjects (Table II). In addition, linear regression analysis of the individual data points also showed a strong relationship between the BMI and the amount of LAR enzyme per $\mathrm{mg}$ of protein in the tissue homogenates (Fig. 4) that was highly statistically significant $(\mathrm{R}=0.843 ; P=0.0006)$.

Although the increase in LAR protein mass was highly cor-

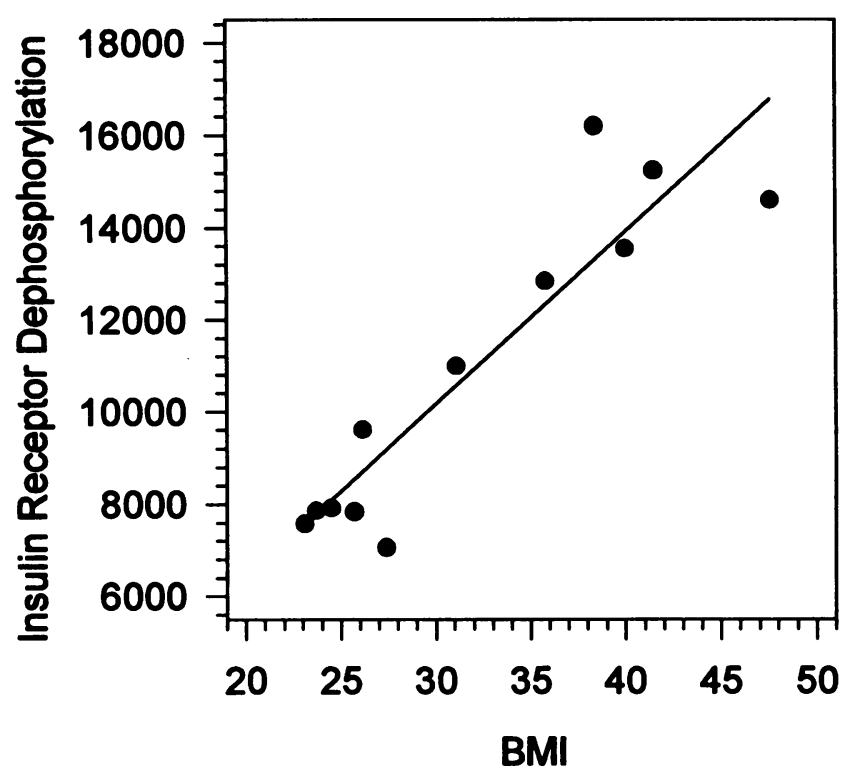

Figure 2. Insulin receptor dephosphorylating activity in adipose tissue from six normal weight and six obese (BMI $>30$ ) individuals. Receptor dephosphorylation was assayed as described in the legend to Fig. 1. PTPase activity was quantitated as the loss of receptor phosphorylation by phosphorimager analysis after incubation with the adipose tissue homogenates. By linear regression analysis of these data, $R=0.918$ and $P<0.0001$. 
Table II. Immunoblot Analysis of PTPase Abundance

\begin{tabular}{llrl}
\hline \multicolumn{1}{c}{ PTPase } & \multicolumn{1}{c}{ Lean } & \multicolumn{1}{c}{ Obese } & $P$-value \\
\hline SH-PTP2 & $5635 \pm 683$ & $8157 \pm 287$ & 0.007 \\
PTPase1B & $4122 \pm 77$ & $5028 \pm 127$ & 0.0001 \\
LAR & $6000 \pm 766$ & $12177 \pm 691$ & 0.0001 \\
\hline
\end{tabular}

PTPase abundance was estimated from immunoblots of adipose tissue homogenates using antibodies to SH-PTP2, PTPase1B, and LAR. The level of PTPase mass is given as arbitrary phosphorimager units that are consistent between the lean and obese samples for each PTPase, but are not comparable between the different PTPases examined.

related with the PTPase activity in the tissue homogenates, these data did not establish that LAR was, in fact, responsible for the bulk of the enhanced insulin receptor dephosphorylating activity that was observed. To evaluate this possibility, we depleted the LAR enzyme from the adipose tissue homogenates by incubation with excess amounts of a specific anti-LAR antibody that immunoprecipitates and inactivates the enzyme, and measured the PTPase activity towards the insulin receptor remaining in the immunoprecipitation supernatant. Under the conditions employed, the excess LAR antibody essentially removed 90-95\% of the enzyme from the tissue homogenate as assessed by immunoblot analysis. Depletion of LAR protein significantly reduced the insulin receptor dephosphorylating activity in the samples from the lean individuals by $40 \%(P<0.05)$, indicating that in normal adipose tissue, LAR represents a significant component of the PTPase activity towards the receptor (Fig. 5). When LAR protein was depleted from the adipose tissue samples from the obese subjects, the increased PTPase activity in the tissue supernatants was essentially normalized with no statistically significant difference between immunodepleted samples from the obese subjects compared with the immunodepleted lean control samples (Fig. 5).

For comparison, adipose tissue homogenates were depleted of SH-PTP2 or PTPase1B by immunoprecipitation and the supernatants were tested for their ability to dephosphorylate the autophosphorylated insulin receptor as substrate. In contrast to the results obtained with LAR immunodepletion, after immunodepletion of $80-90 \%$ of SH-PTP2, the samples from obese subjects maintained a mean 1.45-fold increase in PTPase activ-

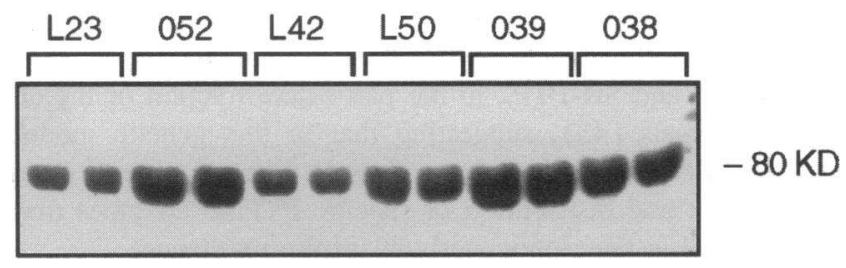

Figure 3. Immunoblot analysis of LAR enzyme protein abundance in adipose tissue from lean and obese subjects. Duplicate samples of tissue homogenates from lean (L23, L42, L50, designated by patient identifying numbers) and obese $(052,039,038)$ subjects were separated on polyacrylamide gels, transferred to nitrocellulose filters and blotted with affinity-purified antibody to the recombinant cytoplasmic domain of LAR as described in Methods. A representative phosphorimage of the immunoblot is shown. The processed, transmembrane domain of LAR migrates at $\sim 80 \mathrm{kD}(55,56)$.

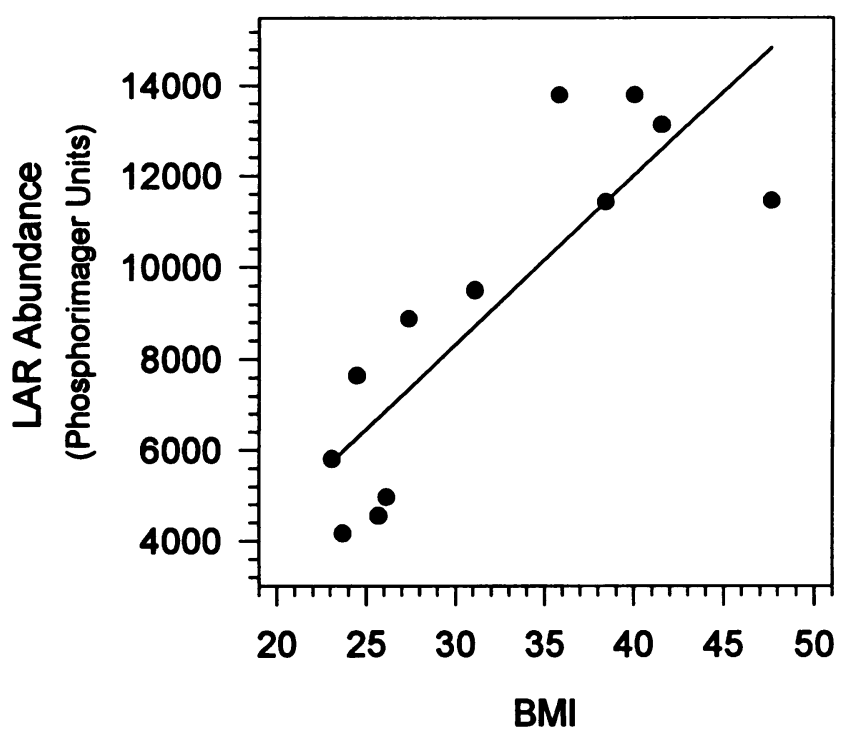

Figure 4. Abundance of LAR enzyme mass in the lean and obese subjects. LAR abundance was measured by immunoblot analysis for adipose tissue homogenates from each of the 12 subjects as described in the legend to Fig. 3. By linear regression analysis of these data, $R$ $=0.843$ and $P=0.0006$.

ity compared to the control subjects ( $95 \%$ confidence interval $1.38-1.53$ ), and after depletion of $75-80 \%$ of PTPase1B, the obese samples exhibited a mean 1.61-fold increase over the control samples (95\% confidence interval 1.44-1.78). Of the three major candidate insulin receptor PTPase enzymes examined, these results provide evidence for a specific role of LAR in the increased PTPase activity observed in the adipose tissue from obese individuals.

\section{Discussion}

The relationship between increasing body adiposity and defects in insulin action in its target tissues is well-characterized but poorly understood at the cellular level (24). In normal volunteers, increasing body mass over a threshold value is highly correlated with decreasing sensitivity to insulin $(25,26)$. In individuals with a genetic predisposition, the insulin resistance associated with obesity can lead to impaired glucose tolerance or frank diabetes. The impact of obesity and insulin resistance on several interrelated risk factors, including the circulating insulin level, hypertension, and dyslipidemias has heightened awareness of this common and important constellation of findings for cardiovascular disease (27).

The site of cellular insulin resistance in adipose tissue in human obesity has not been clearly identified, although defects in both insulin binding capacity and in post-binding signalling have been reported $(2,24,28,29)$. In one report, partially purified receptors from adipocytes of obese subjects had normal insulin receptor kinase activity compared with lean control subjects (30). However, other studies have demonstrated a correlation between decreased insulin receptor autophosphorylation and the loss of insulin signalling to glucose transport and lipolytic pathways in isolated adipocytes from obese patients over a wide range of insulin resistance (31). In obese subjects with Type 2 diabetes mellitus, defects in adipocyte insulin receptor 


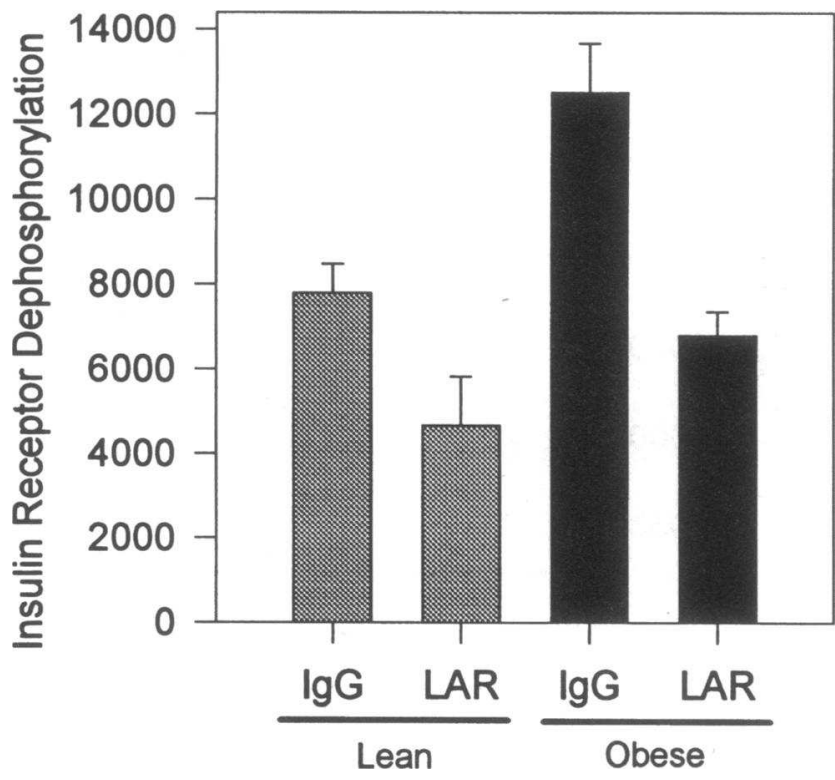

Figure 5. Effect of immunodepletion of LAR from adipose tissue homogenates on the remaining PTPase activity towards the insulin receptor. LAR enzyme protein was depleted by $90-95 \%$ from the adipose tissue homogenates by incubation with excess anti-LAR antibody that immunoprecipitates and inactivates the enzyme. The resulting supernatants were used to assay the PTPase activity towards the insulin receptor as described in Methods. Results are shown for normal rabbit IgG as a control antibody and for anti-LAR antibody for the lean (shaded bars) and obese subjects (solid bars). Statistical calculations, performed among each of the four groups by one-way analysis of variance with Bonferroni's correction, revealed significant differences $(P<0.05)$ between lean control and lean-LAR-depleted samples, between lean control and obese control samples, and between obese control and obeseLAR-depleted samples. The difference between the obese-LAR depleted and the lean-LAR-depleted samples was not statistically significant.

autophosphorylation and in receptor kinase activity towards exogenous substrates have been observed, firmly establishing that the steady-state balance of reversible insulin receptor tyrosine phosphorylation and receptor activation are disrupted in adipose tissue of severly insulin resistant, obese patients $(30,32)$.

Several lines of evidence have recently implicated PTPase enzymes in the pathogenesis of cellular insulin resistance. Since the heterotetrameric insulin receptor does not self-dephosphorylate, the steady-state tyrosine phosphorylation state of receptor sites is determined by a balance between the action of insulin to stimulate receptor autophosphorylation and kinase activation and cellular PTPases which dephosphorylate and inactivate the receptor kinase as well as signalling by tyrosine phosphorylated post-receptor mediators of insulin action (5). Thus, as the physiological regulation of insulin action in normal cells appears to involve cellular PTPases, aberrant regulation or increased activity of PTPases that impact on the insulin action pathway have been implicated in the pathogenesis of insulin-resistant disease states. Furthermore, PTPase inhibitors such as vanadate and related compounds, as potent PTPase inhibitors, have been shown to enhance insulin signalling in vitro and can effectively reduce hyperglycemia in diabetic animal models (33-35). Increases in cytosol or particulate fraction PTPase activity have also been demonstrated in several studies in diabetic rodents (36-39) and in aging (40).

The present study provides the first evidence for increased PTPase activity towards the insulin receptor in adipose tissue from obese human subjects, lending further support to the hypothesis that aberrant expression of PTPases may be an integral part of the pathogenesis of insulin resistance with increasing body mass in this tissue. Previous studies in human subjects, performed with skeletal muscle biopsy material from insulinresistant but nondiabetic Pima Native American subjects showed that basal PTPase activity towards derivatized lysozyme in the particulate fraction of muscle was $33 \%$ higher than in insulin-sensitive controls (41). In further studies, insulin infusion in vivo produced a rapid $25 \%$ suppression of soluble PTPase activity in muscle of insulin-sensitive subjects, but this response was severely impaired in the insulin-resistant subjects. In contrast, a related study by Kusari et al. (42), performed with a different patient population, showed that the skeletal muscle particulate fraction PTPase activity against phosphopeptide substrates was reduced by $21-22 \%$ in obese nondiabetic and non-insulin-dependent diabetic subjects. Furthermore, the basal particulate fraction PTPase activity was positively correlated with the insulin-stimulated glucose disposal rate and weight loss resulted in a significant increase in both the skeletal muscle particulate fraction PTPase activity and in the insulinstimulated glucose disposal rate (42). In relation to the present study, it is not clear how the tissue dephosphorylating activity towards a synthetic phosphopeptide substrate might compare to the dephosphorylation of a native substrate from the insulin signalling pathway, such as IRS-1 or the insulin receptor itself. The main difference between the studies in skeletal muscle and the present work is in the tissue examined, and the contrasting results suggest the possibility that different mechanisms might underlie the observed defects in insulin signalling in muscle versus adipose tissue. Additional studies in human skeletal muscle with the intact insulin receptor as substrate are warranted to explore whether there might be substrate-specific alterations in PTPase activity in insulin-resistant subjects.

In related work, we recently assessed PTPase enzyme activities in subcellular fractions of skeletal muscle in lean $(+/$ ?), obese ( $f a / f a)$ Zucker and diabetic (ZDF/Drt-fa/fa) Zucker rats, a well-characterized rodent model of genetically determined insulin-resistant obesity and diabetes (43). In both the obese and diabetic animals, the muscle particulate fraction PTPase activity was significantly increased by $100-110 \%$ towards the autophosphorylated insulin receptor kinase domain. This enhanced PTPase activity was associated with increases ranging from $40-70 \%$ in the specific immunoreactivity of LAR, PTPase1B, and SH-PTP2 in the particulate fraction of the affected animals (43), suggesting that in this genetic model, which closely resembles human Type II diabetes, alterations in the amount and distribution of specific PTPase enzymes may be involved in the pathogenesis of insulin resistance.

The present results demonstrate that the abundance of LAR is significantly correlated with increasing obesity, and most importantly, that immunodepletion of LAR with neutralizing, immunoprecipitating antibodies normalizes the increased receptor PTPase activity, indicating that LAR has a predominant role in the augmented PTPase activity in the obese state. This enzyme has been a major candidate for regulating the insulin action pathway since it is expressed in insulin sensitive liver, muscle and adipose tissue (5), it is localized to the membrane fraction 
of the cell where the rapid dephosphorylation of the insulin receptor has been demonstrated $(13,14)$, and we have demonstrated in biochemical studies in vitro that its cytoplasmic domain has a catalytic preference for the regulatory phosphotyrosines in the insulin receptor kinase domain (15). In further studies, expression of LAR antisense mRNA in hepatoma cells to reduce LAR mass, insulin receptor autophosphorylation was increased to $150 \%$ of control and insulin-stimulated phosphatidylinositol 3'-kinase activity was further amplified to $300 \%$ over the level observed in cells transfected with the null expression vector (44). Taken together, these studies provide strong evidence that LAR is a physiological modulator of insulin signalling.

A small increase in the abundance of PTPase1B was also noted in the adipose tissue from obese individuals. PTPase1B is a widely expressed enzyme that was first identified as a prominent PTPase in placenta (45). Recently, cell transfection studies have suggested that this PTPase has a potential role in the regulation of tyrosine phosphorylation catalyzed by insulin and insulin like growth factor-I receptors as well as receptors for platelet derived growth factor and epidermal growth factor (46). In the human studies by Kusari et al. (42), the reduced PTPase activity towards phosphopeptide substrates was associated with a mean decrease of $38 \%$ in PTPase1B protein abundance in the diabetic subjects, although substantial variation was observed in both control and diabetic groups. Clearly, further work is needed to assess tissue differences that might exist in the regulation of the abundance of various candidate insulin receptor PTPase enzymes. In addition, the relationship between the abundance of PTPase1B (and other candidate PTPases) and the overall tissue PTPase activity that is measured in subcellular fractions needs to be addressed for skeletal muscle, as we have done for adipose tissue in the case of LAR.

The potential role of SH-PTP2 in insulin signalling is also an important question that is under intensive study in several laboratories. SH-PTP2 associates with tyrosine-phosphorylated IRS-1 by its SH2 domains (47-49). In recombinant in vitro systems, SH-PTP2 has also been shown to associate with the insulin receptor and can be phosphorylated by the insulin receptor kinase $(23,50-52)$. However, several studies in vivo have failed to demonstrate either a direct interaction between SHPTP2 and insulin receptors or any effects of over-expression of the native, catalytically active SH-PTP2 enzyme on the phosphorylation state of the insulin receptor or on insulin signalling in intact cells $(22,53,54)$. Recent evidence suggests that SHPTP2 may have a positive role in growth factor signalling in mammalian cells. Single-cell microinjection of SH-PTP2 antibody, a glutathione-S-transferase fusion construct with the $\mathrm{SH} 2$ domains of SH-PTP2, or IRS-1-derived phosphopeptides that bind to the SH2 domains of SH-PTP2 blocks insulin-stimulated mitogenic signalling (23), and inducible expression of a catalytically inactive (Cys459 $\rightarrow$ Ser) SH-PTP2 mutant in NIH 3T3 fibroblasts over-expressing the insulin receptor blocks insulinstimulated mitogenesis as well as the phosphorylation and activation of MAP kinase by insulin (22). Thus, although there is an increase in SH-PTP2 abundance in adipose tissue from the obese subjects, it is uncertain how this may impact on insulin signalling in this tissue, whether enhancing insulin action or acting in concert with LAR in the insulin resistance that is evident in the obese state.

In summary, these studies provide evidence that supports the hypothesis that increased PTPase activity towards the native insulin receptor is associated with insulin resistance in adipose tissue from obese subjects. Furthermore, a specific candidate PTPase for the insulin action pathway, LAR, has been shown to be increased in obesity and accounts for the observed increase in insulin receptor dephosphorylating activity in the tissue homogenates. Further studies will help characterize the reversibility of this effect in adipose tissue and whether a more generalized increase in LAR enzyme abundance occurs in other insulin sensitive tissues, including liver and skeletal muscle. Finally, these studies raise the possibility that LAR may be involved not only in the insulin resistance of obesity but also more generally in tissue insulin resistance associated with genetically determined diabetes or in more common forms of insulin resistance with increased cardiovascular risk factors.

\section{Acknowledgments}

The authors are grateful to Dr. Jose Caro and Mark Nyce for their assistance in acquiring the adipose tissue samples used in this study. These studies were supported by National Institutes of Health grant DK43396 to Dr. Goldstein.

\section{References}

1. Rabinowitz, D. 1970. Some endocrine and metabolic aspects of obesity. Annu. Rev. Med. 21:241-258.

2. Kolterman, O. G., J. Insel, M. Saekow, and J. M. Olefsky. 1980. Mechanisms of insulin resistance in human obesity: evidence for receptor and postreceptor defects. J. Clin. Invest. 65:1272-1284.

3. Caro, J. F., L. G. Dohm, W. J. Pories, and M. K. Sinha. 1989. Cellular alterations in liver, skeletal muscle, and adipose tissue responsible for insulin resistance in obesity and type II diabetes. [Review]. Diabetes-Metab. Rev. 5:665689.

4. White, M. F., and C. R. Kahn. 1994. The insulin signalling system. J. Biol. Chem. 269:1-4.

5. Goldstein, B. J. 1993. Regulation of insulin receptor signalling by proteintyrosine dephosphorylation. Receptor. 3:1-15.

6. Fischer, E. H., H. Charbonneau, and N. K. Tonks. 1991. Protein tyrosine phosphatases-A diverse family of intracellular and transmembrane enzymes. Science (Wash. DC). 253:401-406.

7. Streuli, M., N. X. Krueger, L. R. Hall, S. F. Schlossman, and H. Saito. 1988. A new member of the immunoglobulin superfamily that has a cytoplasmic region homologous to the leukocyte common antigen. J. Exp. Med. 168:15231530.

8. Chernoff, J., A. R. Schievella, C. A. Jost, R. L. Erikson, and B. G. Neel. 1990. Cloning of a cDNA for a major human protein-tyrosine-phosphatase. Proc. Natl. Acad. Sci. USA. 87:2735-2739.

9. Guan, K. L., R. S. Haun, S. J. Watson, R. L. Geahlen, and J. E. Dixon. 1990. Cloning and expression of a protein-tyrosine-phosphatase. Proc. Natl. Acad. Sci. USA. 87:1501-1505.

10. Freeman, R. M., J. Plutzky, and B. G. Neel. 1992. Identification of a Human src Homology 2-Containing Protein-Tyrosine-Phosphatase. A putative homolog of Drosophila corkscrew. Proc. Natl. Acad. Sci. USA. 89:11239-11243.

11. Ahmad, S., D. Banville, Z. Z. Zhao, E. H. Fischer, and S. H. Shen. 1993 A widely expressed human protein-tyrosine phosphatase containing src homology2 domains. Proc. Natl. Acad. Sci. USA. 90:2197-2201.

12. Ding, W., W. R. Zhang, K. Sullivan, N. Hashimoto, and B. J. Goldstein 1994. Identification of protein-tyrosine phosphatases prevalent in adipocytes by molecular cloning. Biochem. Biophys. Res. Commun. 202:902-907.

13. Mooney, R. A., and D. L. Anderson. 1989. Phosphorylation of the insulin receptor in permeabilized adipocytes is coupled to a rapid dephosphorylation reaction. J. Biol. Chem. 264:6850-6857.

14. Bernier, M., A. S. Liotta, H. K. Kole, D. D. Shock, and J. Roth. 1994. Dynamic regulation of intact and C-terminal truncated insulin receptor phosphorylation in permeabilized cells. Biochemistry. 33:4343-4351.

15. Hashimoto, N., E. P. Feener, W. R. Zhang, and B. J. Goldstein. 1992. Insulin receptor protein-tyrosine phosphatases. Leukocyte common antigen-related phosphatase rapidly deactivates the insulin receptor kinase by preferential dephosphorylation of the receptor regulatory domain. J. Biol. Chem. 267:1381113814.

16. Bradford, M. M. 1976. A rapid and sensitive method for the quantitation of microgram quantities of protein utilizing the principle of protein-dye binding. Anal. Biochem. 72:248-254. 
17. Kasuga, M., M. F. White, and C. R. Kahn. 1985. Phosphorylation of the insulin receptor in cultured hepatoma cells and a solubilized system. Methods Enzymol. 109:609-621.

18. Laemmli, E. K. 1970. Cleavage of structural proteins during the assembly of the head of bacteriophage T4. Nature (Lond.). 227:680-685.

19. Towbin, H., T. Staehelin, and J. Gordon. 1979. Electrophoretic transfer of proteins from polyacrylamide gels to nitrocellulose sheets: procedure and some applications. Proc. Natl. Acad. Sci. USA. 76:4350-4354.

20. Hashimoto, N., W. R. Zhang, and B. J. Goldstein. 1992. Insulin receptor and epidermal growth factor receptor dephosphorylation by three major rat liver protein-tyrosine phosphatases expressed in a recombinant bacterial system. Biochem. J. 284:569-576.

21. Harlow, E., and D. Lane. 1988. Antibodies: A Laboratory Manual. Cold Spring Harbor Laboratory Press, Cold Spring Harbor, NY.

22. Milarski, K. L., and A. R. Saltiel. 1994. Expression of catalytically inactive Syp phosphatase in 3T3 cells blocks stimulation of mitogen-activated protein kinase by insulin. J. Biol. Chem. 269:21239-21243.

23. Xiao, S., D. W. Rose, T. Sasaoka, H. Maegawa, T. R. Burke, P. P. Roller, S. E. Shoelson, and J. M. Olefsky. 1994. Syp (SH-PTP2) is a positive mediator of growth factor-stimulated mitogenic signal transduction. J. Biol. Chem. 269:21244-21248

24. Caro, J. F. 1991. Clinical Review 26: Insulin resistance in obese and nonobese man. J. Clin. Endocrinol. Metab. 73:691-695.

25. Campbell, P. J., and J. E. Gerich. 1990. Impact of obesity on insulin action in volunteers with normal glucose tolerance: Demonstration of a threshold for the adverse effect of obesity. J. Clin. Endocrinol. Metab. 70:1114-1118.

26. Boden, G. 1993. Effects of age and body fat on insulin resistance in healthy men. Diabetes Care. 16:728-733.

27. Reaven, G. M. 1988. Banting lecture 1988. Role of insulin resistance in human disease. Diabetes. 37:1595-1607.

28. Olefsky, J. M. 1976. Insulin binding to adipocytes and circulating monocytes from obese patients. J. Clin. Invest. 57:1165-1172.

29. Ciaraldi, T. P., J. M. Molina, and J. M. Olefsky. 1991. Insulin action kinetics in adipocytes from obese and noninsulin-dependent diabetes mellitus subjects: identification of multiple cellular defects in glucose transport. J. Clin. Endocrinol. Metab. 72:876-882.

30. Freidenberg, G. R., R. R. Henry, H. H. Klein, D. R. Reichart, and J. M Olefsky. 1987. Decreased kinase activity of insulin receptors from adipocytes of non-insulin-dependent diabetic subjects. J. Clin. Invest. 79:240-250.

31. Takayama, S., C. R. Kahn, K. Kubo, and J. E. Foley. 1988. Alterations in insulin receptor autophosphorylation in insulin resistance: Correlation with altered sensitivity to glucose transport and anti-lipolysis to insulin. J. Clin. Endocrinol. Metab. 66:992-990.

32. Sinha, M. K., W. J. Pories, E. G. Flickinger, D. Meelheim, and J. F. Caro. 1987. Insulin-receptor kinase activity of adipose tissue from morbidly obese humans with and without NIDDM. Diabetes. 36:620-625.

33. Meyerovitch, J., P. L. Rothenberg, Y. Shechter, S. Bonner-Weir, an C. R. Kahn. 1991. Vanadate normalizes hyperglycemia in two mouse models of non-insulin dependent diabetes mellitus. J. Clin. Invest. 87:1286-1294.

34. Posner, B. I., R. Faure, J. W. Burgess, A. P. Bevan, D. Lachance, G. Y. Zhangsun, I. G. Fantus, J. B. Ng, D. A. Hall, B. S. Lum, and A. Shaver. 1994 Peroxovanadium compounds: a new class of potent phosphotyrosine phosphatase inhibitors which are insulin mimetics. J. Biol. Chem. 269:4596-4604.

35. Shisheva, A., O. Ikonomov, and Y. Shechter. 1994. The protein tyrosine phosphatase inhibitor, pervanadate, is a powerful antidiabetic agent in streptozotocin-treated diabetic rats. Endocrinology. 134:507-510.

36. Meyerovitch, J., J. M. Backer, and C. R. Kahn. 1989. Hepatic phosphotyrosine phosphatase activity and its alteration in diabetic rats. J. Clin. Invest. 84:976983.

37. Begum, N., K. E. Sussman, and B. Draznin. 1991. Differential Effects of Diabetes on Adipocyte and Liver Phosphotyrosine and Phosphoserine Phosphatase Activities. Diabetes. 40:1620-1629.

38. Boylan, J. M., D. L. Brautigan, J. Madden, T. Raven, L. Ellis, and P. A. Gruppuso. 1992. Differential regulation of multiple hepatic protein tyrosine phosphatases in alloxan diabetic rats. J. Clin. Invest. 90:174-179.
39. Goren, H. J., and D. Boland. 1991. The 180,000 Molecular weight plasma membrane insulin receptor substrate is a protein tyrosine phosphatase and is elevated in diabetic plasma membranes. Biochem. Biophys. Res. Commun. 180:463-469.

40. Nadiv, O., M. Shinitzky, H. Manu, D. Hecht, C. T. Roberts, Jr., D. LeRoith, and Y. Zick. 1994. Elevated protein tyrosine phosphatase activity and increased membrane viscosity are associated with impaired activation of the insulin receptor kinase in old rats. Biochem. J. 298:443-450.

41. McGuire, M. C., R. M. Fields, B. L. Nyomba, I. Raz, C. Bogardus, N. K. Tonks, and J. Sommercorn. 1991. Abnormal regulation of protein tyrosine phosphatase activities in skeletal muscle of insulin-resistant humans. Diabetes. 40:939-942.

42. Kusari, J., K. A. Kenner, K. I. Suh, D. E. Hill, and R. R. Henry. 1994. Skeletal muscle protein tyrosine phosphatase activity and tyrosine phosphatase $1 \mathrm{~B}$ protein content are associated with insulin action and resistance. J. Clin. Invest. 93:1156-1162.

43. Ahmad, F., and B. J. Goldstein. 1995. Increased abundance of specific skeletal muscle protein-tyrosine phosphatases in a genetic model of obesity and insulin resistance. Metabolism. In press.

44. Kulas, D. T., W. R. Zhang, B. J. Goldstein, R. W. Furlanetto, and R. A Mooney. 1995. Insulin receptor signalling is augmented by antisense inhibition of the protein-tyrosine phosphatase LAR. J. Biol. Chem. 270:2435-2438.

45. Charbonneau, H., N. K. Tonks, S. Kumar, C. D. Diltz, M. Harrylock, D. E. Cool, E. G. Krebs, E. H. Fischer, and K. A. Walsh. 1989. Human placent protein-tyrosine-phosphatase: amino acid sequence and relationship to a family of receptor-like proteins. Proc. Natl. Acad. Sci. USA. 86:5252-5256.

46. Lammers, R., B. Bossenmaier, D. E. Cool, N. K. Tonks, J. Schlessinger, E. H. Fischer, and A. Ullrich. 1993. Differential activities of protein tyrosine phosphatases in intact cells. J. Biol. Chem. 268:22456-22462.

47. Sun, X. J., D. L. Crimmins, M. G. Myers, M. Miralpeix, and M. F. White 1993. Pleiotropic insulin signals are engaged by multisite phosphorylation of IRS1. Mol. Cell. Biol. 13:7418-7428.

48. Kuhné, M. R., T. Pawson, G. E. Lienhard, and G. S. Feng. 1993. The Insulin Receptor Substrate-1 Associates with the SH2-Containing Phosphotyrosine Phosphatase Syp. J. Biol. Chem. 268:11479-11481.

49. Sugimoto, S., T. J. Wandless, S. E. Shoelson, B. G. Neel, and C. T. Walsh 1994. Activation of the SH2-containing protein tyrosine phosphatase, SH-PTP2, by phosphotyrosine-containing peptides derived from insulin receptor substrate1. J. Biol. Chem. 269:13614-13622.

50. Maegawa, H., S. Ugi, O. Ishibashi, R. Tachikawaide, N. Takahara, Y Tanaka, Y. Takagi, R. Kikkawa, Y. Shigeta, and A. Kashiwagi. 1993. Src homology-2 domains of protein tyrosine phosphatase are phosphorylated by insulin receptor kinase and bind to the $\mathrm{COOH}$-terminus of insulin receptors in vitro. Biochem. Biophys. Res. Commun. 194:208-214.

51. Maegawa, H., S. Ugi, M. Adachi, Y. Hinoda, R. Kikkawa, A. Yachi, Y. Shigeta, and A. Kashiwagi. 1994. Insulin receptor kinase phosphorylates protein tyrosine phosphatase containing SRC homology 2 regions and modulates its PTPase activity in vitro. Biochem. Biophys. Res. Commun. 199:780-785.

52. Ugi, S., H. Maegawa, J. M. Olefsky, Y. Shigeta, and A. Kashiwagi. 1994. Src homology 2 domains of protein tyrosine phosphatase are associated in vitro with both the insulin receptor and insulin receptor substrate-1 via different phosphotyrosine motifs. FEBS (Fed. Eur. Biochem. Soc.) Lett. 340:216-220.

53. Vogel, W., R. Lammers, J. T. Huang, and A. Ullich. 1993. Activation of a phosphotyrosine phosphatase by tyrosine phosphorylation. Science (Wash. DC). 259:1611-1614.

54. Kuhné, M. R., Z. Z. Zhao, J. Rowles, B. E. Lavan, S. H. Shen, E. H. Fischer, and G. E. Lienhard. 1994. Dephosphorylation of insulin receptor substrate 1 by the tyrosine phosphatase PTP2C. J. Biol. Chem. 269:15833-15837.

55. Streuli, M., N. X. Krueger, P. D. Ariniello, M. Tang, J. M. Munro, W. A. Blattler, D. A. Adler, C. M. Disteche, and H. Saito. 1992. Expression of the receptor-linked protein tyrosine phosphatase LAR: proteolytic cleavage and shedding of the CAM-like extracellular region. EMBO (Eur. Mol. Biol. Organ.) J. 11:897-907.

56. Yu, Q., T. Lenardo, and R. A. Weinberg. 1992. The N-terminal and Cterminal domains of a receptor tyrosine phosphatase are associated by non-covalent linkage. Oncogene. 7:1051-1058. 